\title{
Virtual Learning Environment (VLE):
}

\section{A Web-based Collaborative Learning System}

\author{
Charles Y. Y. Cheng \\ Department of Computer Science \\ The University of Hong Kong \\ yycheng2@cs.hku.hk
}

\author{
Jerome Yen \\ Department of Computer Science \\ The University of Hong Kong \\ jyen@cs.hku.hk
}

\begin{abstract}
Using Internet and WWW to support teaching or learning has become a trend in modern higher education. However, most distant-learning or virtuallearning sites are still limited to the dissemination of teaching materials. Neither the strengths of Internet and $W W W$ have been maximized nor the functions have been fully utilized, for instance, supporting autonomous, exploratory, interactive and collaborative learning. The University of Hong Kong (HKU) has developed a virtual learning system, called Virtual Learning Environment $(V L E)$, to prove that such kind of learning is possible with Internet and WWW technologies.
\end{abstract}

\section{Introduction and Motivation}

In recent years many researchers have tried to use the emerging computer and communication technologies to construct effective teaching and learning environments. Some of the emerging results are promising. For example, through the use of a virtual classroom, researchers at New Jersey Institute of Technology have shown that computer communication is a possible way of delivering effective teaching. In particular, the results of their empirical studies have pointed to the superiority of the virtual classroom for well-motivated and well-prepared students provided that they have access to the necessary equipment [9].

Similarly, Leidner and Jarvenpas suggest that technology can influence the pace and content of learning, as well as the purpose of instruction [19]. In this context, they point out that technology can be used to transform education and to re-examine the efficacy of the traditional modes of delivery of educational material, which are bounded by temporal and spatial constraints. Alavi et al. in the same line of thought, also suggest that computer-mediated collaborative learning is superior to the traditional modes of learning because it facilitates active learning and construction of knowledge [1]. The results of their empirical study of a group of MBA students show that desktop video conferencing is a viable medium for collaborative distance learning.

In sum the emerging research shows that computermediated learning environment has great potentials in facilitation of collaborative learning, in promotion of the learners' autonomy in controlling their own learning pace, and in enhancement of the instruction design. In this decade, the increasing popular Internet usage brings us not only a new way of information assimilation but also a change in the social structure of mankind. How to apply the Internet and WWW technologies to support teaching and learning is one of the most frequently and widely discussed topics over the Internet, newspapers, conferences. In the human history, besides the paper and printing technology, information technologies (IT) might have created the most significant impacts [3,5]. Among all the IT, Internet and WWW technologies probably have the highest potential in pushing the paradigm shift in education [20].

There is no exception for University of Hong Kong to search for decent learning technology so as to pursue educational and academic excellence and to maintain its leading role among local learning institutes. An Ac Hoc Group for Learning Technology was formed and its mission statements spelt out the local needs for new learning technology.

“... students, administrators, academics, staff, and the citizens of Hong Kong work together to create a technology-rich community implementing and integrating the best learning technologies into educational practice.

... students throughout Hong Kong, China, and the world enroll in HKU courses as the University fulfills its historical role providing superior tertiary education by means of the very best academic staff, 
pedagogy, and the intelligent use of learning technologies."

(Href 1)

Internet Application and Digital Library Group of the Department of Computer Science of HKU, as a member of HKU community, is also pressed by the need. To prove that the above vision can be fulfilled with the Internet and WWW technologies, we have developed a web-based learning system, called Virtual Learning Environment (VLE). VLE, by making use of the asynchronous and programmable nature of the WWW, aims to provide support not only to learning materials generation and dissemination, but also to collaborative teaching and learning.

The rest of this paper is arranged as following: Problems of traditional education styles and the paradigm shift will be discussed in section 2 . On-line education and Web-based learning systems will be discussed in section 3. Design philosophy of VLE will be discussed in section 4. Section 5 discusses system implementation. The experiments currently underway are discussed in section 6 . This paper is concluded with a discussion on the potential impacts and future development of VLE.

\section{Paradigm Shift}

\subsection{The problem of traditional education style}

Present day schooling, or the traditional classroom learning, should not be merely treated as a kind of natural human activity like eating and sleeping, but as a social product introduced by the middle class at the end of the 19th century. Since then, "social and professional knowledge was divided into the bite-sized chunks that we now recognize as mathematics, social studies, reading, language, science, and art." [10] (pp.87). Learning activities, to most people, are packaged into certain kinds of defined subjects, in a confined environment, for a decent proportion of one's life span. Although such schooling did provide a mass education to the public to satisfy the social and economic needs, it may not be an ideal education pattern for mankind.

In fact, Hutchison describes the traditional education style as perverse unnaturalness [11]. Envisaging the rapidly changing world in which new technologies relentlessly redefining the way people work and live, he suggests that

"it may not merely be an anachronism to continue to embrace the model of the traditional residential university as the primary locus of learning -- it may arguably be an impediment to appropriate learning and ultimately a threat to growth, both economic and personal."

If students can log into the campus learning network at home and receive quality or even better education as he is physically present at school, there is no reason we have to insist on following the traditional learning pattern. As we envisage the prevalence of Internet connected home computers in homes and office, this new mode of learning will certainly be more and more accessible by the home-users. The unprecedented convenience and the versatility of computer based learning will bring a new era of learning with which the present schooling cannot compete.

\subsection{The Paradigm shift}

When we examine the contemporary learning theories, we find that some notions about teaching and learning are changing drastically. Instruction-based learning pattern is being challenged. New learning paradigms are forming. A summary of the paradigm shift in education is as follows:

Educational focus is shifting from teacher-centered to student-centered;

Teaching approach is moving from lecturing monotonously to facilitating students' autonomous and independent learning;

Learning style is shifting from passive learning to active and collaborative learning;

At the same time, we noticed many learning institutes in North America and Asia have started to use Internet and WWW to support teaching or learning (see the table below) with the understanding that technology can be a better vehicle to support the education of the new era.

Table 1. Examples of research on Internet-Based Learning

\begin{tabular}{|c|}
\hline $\begin{array}{c}\text { The Virtual Classroom } \\
\text { New Jersey Institute of Technology } \\
\text { (Hiltz, S.R., Turoff, M., 1994) }\end{array}$ \\
\hline \multicolumn{1}{|c|}{ The Virtual Classroom } \\
The University of West Florida [Href2] \\
\hline $\begin{array}{l}\text { The World Lecture Hall } \\
\text { University of Texas [Href3] } \\
\text { ElectronicCourse Reserves } \\
\text { The University of Connecticut [Href4] }\end{array}$ \\
\hline
\end{tabular}

In our studies, we find that some of the above Internet education enable dissemination of teaching materials only. Hardly can we see the educational rationales of the construct which are consistent with the aforementioned paradigm shift. On the other hard, it is a pity that the potential of the Internet and WWW was not maximized. It is actually able to enhance coordination, interaction 
and collaboration among the students and instructors. We believe that supporting autonomous, exploratory, interactive and collaborative learning should also be the major focus of using the Internet and WWW technologies in education.

This view is best presented by a report published by the University Grant Council (UGC) of Hong Kong Government in October, 1996 [HREF5].

Technology will improve the quality and range of teaching and learning by providing:

- better access to information;

- more active learning as opposed to passive listening to lectures;

- more learning (and teaching) at times and places most convenient to students;

- more opportunities for collaborative learning (students working together on projects);

- 'mass customization,' wherein technology-mediated learning experiences are tailored to individual students' needs." (par. 26.13)"

\section{On-line Education and Web-based learning system}

The rapid development of the Internet and most remarkable WWW technologies do not simply enable us to build a Web-page for task-specific activities (e.g. Frequently asked questions (FAQ), news group discussion, teleconferencing). On the contrary, they can make it possible to build integrated learning and teaching environment which supports various modes of learning activities: self-paced learning, collaborative project team, teleconferencing, etc. Furthermore, the penetrating power of the Internet is great enough to enable the on-line learning systems to deliver education to special learning sites where the academic can hardly reach, for instance, the adult education centers, company training rooms, the Internet cafes, special schools for students with learning or physical disabilities, public libraries, prisons, selected homes [11]. It is worth noting that the tremendous technological developments in Internet technology have brought us an unprecedented excitement and opportunity in education.

A recent news report released by Cnet [Href6], one of the leading on-line publishing companies, suggested that an Internet-based learning system:

"use a wide range of technology to make learning as easy and collaborative as possible. While the level of sophistication varies, standard to most Web courses are communication systems, such as email, real-time chat rooms, and threaded discussion groups that let students interact with instructors and each other online."

More specifically, this kind of Internet-based learning system should have the following learning and teaching features:

Table 2. The features of On-line Education

\begin{tabular}{|c|c|}
\hline $\begin{array}{c}\text { Electronic } \\
\text { lecture notes }\end{array}$ & $\begin{array}{c}\text { - providing with student-customized } \\
\text { learning materials }\end{array}$ \\
\hline Message system & $\begin{array}{c}\text { - connecting the course participants } \\
\text { so as to achieve communication and } \\
\text { collaboration purposes }\end{array}$ \\
\hline Discussion & $\begin{array}{c}\text { - enabling real-time chat or threaded } \\
\text { discussions }\end{array}$ \\
\hline $\begin{array}{c}\text { Interactive } \\
\text { assessment }\end{array}$ & $\begin{array}{c}\text { - generating on-line quizzes which } \\
\text { are marked by the server }\end{array}$ \\
\hline $\begin{array}{c}\text { Course creation } \\
\text { Course } \\
\text { management }\end{array}$ & $\begin{array}{c}\text { - allowing the instructors to } \\
\text { system which helps to organize the } \\
\text { course materials }\end{array}$ \\
\hline $\begin{array}{c}\text { Student } \\
\text { management }\end{array}$ & $\begin{array}{c}\text { - having a database management } \\
\text { system which helps to organize the } \\
\text { student information and to track the } \\
\text { individual user so that customized } \\
\text { services can be provided. }\end{array}$ \\
\hline
\end{tabular}

Currently, some of these web-based learning systems have been developed to deliver real training or academic courses over the Internet. They range from grass-roots volunteer efforts, for example, Blue Web'n Library [Href7], Netday [Href8], and academic institutions, such as SUNY Virtual Classroom [Href9], the CORAL system of the National Chiao Tung University in Taiwan [Href10], to the commercial sector, such as, Zdnet University [Href11] and the Spectrum University [Href12]. Some generic system products are also available, for example, the FirstClass [Href 13], Topclass [Href14], WebCT [Href15], which claim to provide easy to set-up program for creating on-line training courses.

Many of these systems place much emphasis on the courseware production and the Graphical User Interface (GUI). Although these systems do provide fancy interface and abundant course materials in multimedia format for the on-line learners, we could not agree with their educational view. Their focus is more on re-creating the usual classroom practice on the net, rather than transforming the existing learning system to a more pedagogical sound learning environment on the Internet. 


\section{Theoretical Foundation}

The problems encountered in the design of good Internet-based learning delivery system cannot be resolved or even formulated without addressing the fundamental theory of learning. In general, we all have certain ideas of what learning is albeit seldom being able to give a full description. Gagne has given a rather precise definition of learning [7].

"a process of which man and the animals are capable. It typically involves interaction with the external environment (or with a representation of this interaction, stored in the learner's memory). Learning is inferred when a change or modification in behavior occurs that persists over relatively long periods during the life of the individual." (pp.3).

Despite the fact that a lot of postulate and notions have been proposed, the mechanism of how people learn is still a mystery to even the educational specialists.

Essentially, the approaches of understanding learning can be reduced to two major theoretical positions: the behaviorist and the cognitist. Wittrock has attempted to give a clear description on the difference between these two models of learning [27],

"behaviouristic models, as different from cognitive models, relate characteristics of environments directly to learned behavior, .... On the contrary, people who develop cognitive models of instruction believe that it is more scientifically productive to study how environmental variables, including teacher classroom behavior, influence learners' mental process" (pp.75, 76).

From the behaviorist's point of view, learning could be understood and described by studying only overt behavior and its consequences in the environment. It is not needed to understand the learners' internal learning process to describe the learning effect. Although behaviorist theory has contributed a lot to the understanding of learning, Gagne realises that "evidence has been obtained that suggests there is more to learning than what behaviorist theory is able to describe" [7] (pp.11). Therefore, with an aim to design an instructional environment that can cater the learners' mental need, it is crucial to understand the cognitists' notions of learning.

There are three main schools of cognitive learning: the Information Processing Theory which stresses the internal learning process of learners, Constructivism of which the emphasis is on the knowledge construction, and the Collaborate Learning advocating the effectiveness of knowledge acquisition through cooperation.

\subsection{Information Processing Theory}

\section{Learning process}

According to Gagne \& Driscoll, the processes presumed to account for learning are regarded as certain kinds of transformations of input to outputs in a fashion somewhat analogous to the operation of a computer [7].

Kozma suggested that information is organized as a set of nodes and links, or a Semitic network in long-term memory [18]. The nodes represent conceptual units whereas the connections or links between the nodes define some properties of those units.

Information from either short-term or long-term memory, when retrieved, passes to the response generator, which transforms the information into neural message to activate the effectors. The effectors will then produce the observable performance which can be ascribed as the learning outcomes of the learner. If the action produced is matched with the expected outcomes of the mediators (e.g. the teachers), the learner is said to have learned $[6,7]$.

Having said that, there is no guarantee that an expected learning will take place even if the right kind of information has been fed into the received by such a learning process. It relies on the other structures shown in Figure 1, the executive control and expectancies.

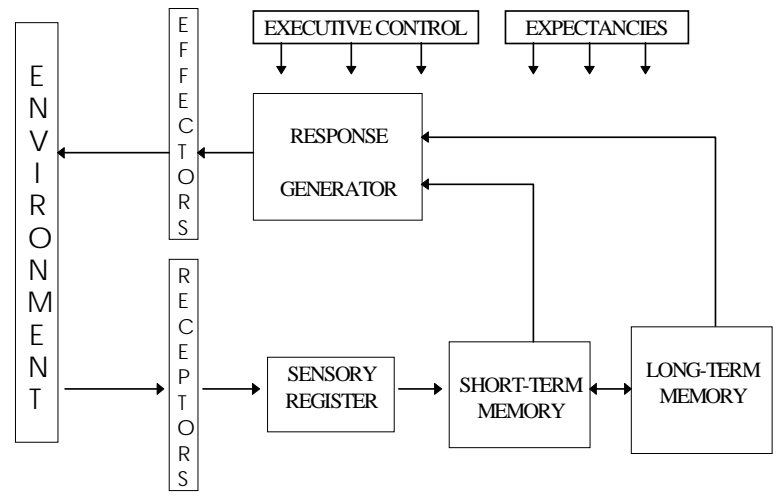

Figure 1 The basic model of learning and memory underlying modern information processing theories. (Adapted from Gagne and Driscoll, 1988, p.13)

According to Gagne,

"these are processes that activate and modulate the flow of information during learning. For example, learners have an expectancy of what they will be able to do once they have learned, and this in turn may affect how an external situation is perceived, how it is encoded in memory, and how it is transformed into performance. The executive control structure governs the use of cognitive strategies, 
which may determine how information is encoded when it enters long-term memory, or how the process of retrieval is carried out, among other things." [6] (p.10)

\section{Implication for Instruction Design}

Corresponding to the steps of learning, the following events of instruction proposed by Gagne should be noted:

a) Stimulation to gain attention to ensure the reception of stimuli.

b) Informing learners of the learning objective, to establish appropriate expectancies.

c) Reminding learners of previously learned content for retrieval from LTM.

d) Clear and distinctive presentation of material to ensure selective perception.

e) Guidance of learning by suitable semantic encoding.

f) Eliciting performance, involving response generation

g) Providing feedback about performance

h) Assessing the performance, involving additional response feedback occasions

i) Arranging variety to aid future retrieval and transfer

\subsection{Constructivism}

The basic assumption of constructivism is that knowledge is not some objective chunks of information that can be transmitted to the learners externally; rather, it is the meaning or concept constructed internally within the learners' mind. It is constructed by interpreting perceptual experiences in term of prior knowledge, current mental structures, and existing belief set [13]. The mind is instrumental and essential in interpreting, objects, and perspectives on the external world, and these interpretations comprise a knowledge base that is personal and individualistic [13, 19]. Therefore, there is no fixed meaning for an object but individuals' experience defining a particular context for that object.

Some constructivists, emphasize that the individual constructions of knowledge are derived from interactions of the learners with the social environment. The social environment provides a set of experiences from which the individual tests understanding and adopts group norms [4]. From social constructivists' viewpoint [10], "experience", including both the physical context for learning and the activities of the learner determines how something is learned. The activities within this kind of social environment should comprise the following features:

" 1 . Ownership by the learner - the instruction must support them in assuming responsibility for establishing and monitoring their goals and strategies.

2. Project based - the learning activity has a purpose that goes beyond simply demonstrating mastery of the local tasks. The purpose for a learning activity is driven by the global project context " [10] (p.90).

\section{Implication for Learning-Environment Design}

Winn criticizes the prescriptive nature of nonconstructivists instruction design by arguing that human behavior and understanding cannot be predicted and people's cognitive systems are highly heterogeneous (i.e. with many different worlds) [26]. He further suggests that traditional instruction design is only good for improving automatic performance. To attain genuine comprehension, students are required to construct their own knowledge. Following his argument, he proposes a constuctivist's design framework. The procedures are as follows:

1. Use 'empty technologies', technologies that are not designed with any particular content or instruction method in mind such as the hypermedia systems. They should be adopted to provide a design shell that supports flexible navigation and sharing.

2. Create interfaces that should be user customized, consistent and as transparent to the students as possible. Virtual reality is a good choice for this kind of interface design.

3. Pertain to the intention of the designer.

In Winn's word, the guidelines for making learning environment are .[26] (pp.207-208):

a) If the intention is for students to learn about the learning environment itself, the main issue facing the designer is the degree to which the student's interaction with the environment should be governed by rules. If students are expected to understand the domain in particular ways, the rules should eventually be enforced.

b) If the intention is for students to use the learning environment as a means to exercise their imaginations or to solve problems, the rules should not be enforced. This means that the only "correct" outcomes of interaction with the environment are those that satisfy the student.

c) If students are to construct their own learning environments, then they need to decide for themselves how rule-governed those environments shall be.

d) Requests for suggestions and help should not be confused. Unsolicited help should only be given when students are having difficulties that clearly 
prevent them from constructing their understanding of the learning environment.

Knuth and Cunningham identified three dimensions of learning environment which can be well supported, namely, information, processes and reflexivity [17]. Knowing how to learn is more important than knowing what to learn.

\subsection{Collaborative learning}

According to Alavi et al, collaborative or group learning is an interpersonal process in which students work together cooperatively to complete a problemsolving task designed to promote learning [1]. Through conversation, discussion and debate, participants offer explanations, interpretations, and resolutions to problems which lead to social construction of knowledge, as well as development and internalization of meaning and understanding. Learning occurs as individuals exercise, verify, solidify, and improve their mental models. The contribution of different understanding leads to a new, shared knowledge [19]. It should be noted that teacher's role is no more the process controller but an active participant in the learning process instead. Knowledge is not something that is "delivered" to students. On the contrary, it is something that emerges from active dialogue among those who seek to understand and apply concepts and techniques [8].

As Alavi et al pointed out, ample evidences have shown that collaborative learning is superior than the traditional modes of learning (e.g. individual or competitive learning situations) in terms of learning achievement, student satisfaction with the learning process and outcomes, and quality of interpersonal relationships and the emotional climate [1]. However, it needs extra effort to make the collaborative learning environment complete. Simply placing individuals in groups and telling them to work together as reminded by Johnson \& Johnson [12], does not in and of itself promote productivity. In fact, undesired effects may yield if the cooperative environment is not structured correctly, especially under the traditional face-to-face conditions.

Johnson and Johnson suggest that there are five essential components of cooperative learning [12]:

a) Positive Interdependence: the students have the responsibilities to learn the assigned material and ensure that all members of their group learn the assigned material.

b) Face-to-face Promotive Interaction: The essence is to put all the group members in a certain social setting so that they can interact and influence each other. c) Individual Accountability and Personal Responsibility: It is to ensure each student is accountable to do his or her fair share of the group's work.

d) Interpersonal and Small Group Skills: It means that the students must be taught the social skills required to co-work with each other. It is vital in handling conflicting situation.

e) Group Processing: The purpose is to clarify and improve the effectiveness of the members in contributing to the collaborative efforts to achieve the group's goals.

Regarding the component of face-to-face interaction, it is suggested that the cost-effective, advanced information technologies such as teleconferencing may be able to provide an equally good social environment [1]. This is also one of the main themes of our research subject.

Implication for collaborative environment design For making a learning environment that consists of collaborative learning, the following points should be taken into consideration [19]:

a) Instructor plays an essential role to facilitate maximum information and knowledge sharing among learners.

b) Instructor should provide feedback as well as the peers giving feedback.

c) The need for cooperative assessment strategies.

\section{Design Philosophy of Effective Learning Environment}

Although Constructivism seems to dominate the mainstream educational research, there is still no consensus on which is a better notion. As a matter of fact, the school of instruction theory is more acceptable in real practice as it is easier to monitor. Perhaps they are all decent theories, standing from different angles, describing the different facets of a complex system. It all depends on the maturity and the social-cultural background of the learners, the situation of the learning environment and the content of learning materials to decide which is a more suitable theory for that particular application. It becomes more relevant if the individual learning activity can be customized.

In general, if we follow Jonassen et al's suggestion the knowledge growth is best viewed as a phase change from introductory learning to advanced learning and then to expert learning, it becomes apparent of when to adopt a particular theory [13]. The choice depends on the learning phase to be served. Jonassen gives a full account for the relationship between the design of learning environment and the learning theories adopted, 
"We believe that the initial knowledge acquisition phase is better served by instructional techniques that are based upon classical instructional design techniques. Classical instructional design is predicted upon predetermined learning outcomes, constrained and sequential instructional interactions, and criterion-reference evaluation. We believe that constructive learning environments may be used during the latter stages of initial knowledge acquisition, and that they represent rich and meaningful environments for initial knowledge learners." (pp.232)

However, in a traditional classroom, that would be a difficult task, if not impossible, for even the most skillful teacher, to apply the seemingly contrasting theories to a class of mixed characters and abilities. This is where the technology applies. In the following, we will describe how we create such kind of systems using the web-based technology.

\section{System Design of VLE}

The virtual Learning Environment (VLE) was designed with the general instruction design and constructive learning environment in mind, aiming to provide a simple-to-use interface to support the development of web-based lecture resource materials, question and answer facilities between teachers and students as well as video and asynchronous conferencing among students and staff..

Using the system, staff members can develop webbased multimedia resources without learning to master any programming language. Conveniently, it provides access to several powerful Internet search agents as well as a well-designed system of bookmarks that provides a good infrastructure and framework for the sharing of resources and collaboration.

\subsection{Design Model}

The VLE system can be represented by the following model:

A VLE shell is a web which is designed to provide the guided navigation and communicative infra-structure to the users. Following the instruction and the guidance, the learners can access their favorite learning activities. The learning activities can be lecture notes, lecture video archives, simulation program, queries, self-tests or quiz. Based on the content and the presentation of the learning activities, they are categorized into four learning zones as shown in Figure 2.

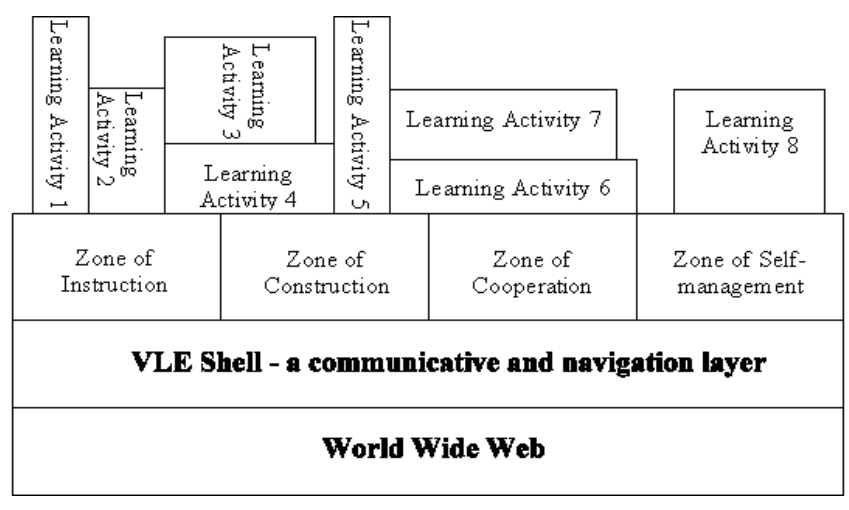

Figure 2. The VLE system model

\section{Zone of Instruction -}

The learning materials and activities in this zone are:

a. Organized learning material with detail guideline, e.g., an on-line course-book.

b. Clear and distinctive presentation of materials

c. Stimulation to gain attention to ensure reception of stimuli; e.g. using meaningful images, sound, and animation.

d. Allow learners to ask and to get feed back in an organized manner within a very short period of time.

e. With assessment instruments such as test or quiz to reinforce the learning outcome.

\section{Zone of construction -}

The learning materials and activities in this zone can be:

a. Discussion forum which foster sharing atmosphere within the learning community, e.g. chat room or bulletin board.

b. Construction tools so that the learners can construct their own learning environment, e.g. a note book or scrap book for them to collate and to organize their findings after studying the course materials or surfing the WWW.

c. Reflexivity tools which enable the learners to reflect on their own learning process. A reflection report which the course tutor can give remark or comment may be a good instrument to serve this purpose.

\section{Zone of Cooperation -}

The learning materials and activities in this zone can be: 
a. Collaborative work with common objectives and same assessment criteria set for the learners so that the group learners can take up their individual responsibilities to share, to work together and to negotiate.

b. Project based so that the learning outcome can be substantiated to be something real for example, to produce a project web.

\section{Zone of self-management -}

The activities in this zone are not necessarily related to the designed principals we have discussed. This is made mainly for the learners to organize their learning activities and to administer their personal information. For example, to enroll or drop a subject course, to update their personal information so that they can be kept in touch with the VLE community.

Teachers and students can play different roles in different learning activities via the Internet. For instance, in the case of course instruction, the teacher can present his or her instruction material by using the authoring tool of our system where the students can read using the book' function of our system.

\subsection{Technology Employed}

VLE system consists of a web server to provide the HTTP, FTP services, a SQL Server to provide the database management and a set of small server programs to provide the multimedia, interactive and teleconferencing functionality. In our system, we adopt the Information Server (IIS) 3.0 as our Web server, MSSQL 6.5 as our Database server and Active Server Pages (ASP), a server-side scripting environment, to create and run dynamic, interactive Web server applications such as form handling. The overall architecture of our system is illustrated in Figure 3.

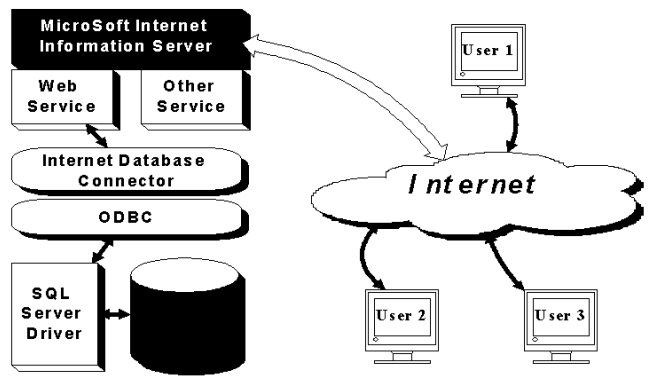

Figure 3. The VLE system architecture

\subsection{Structure of the VLE}

The structure of VLE uses a spatial metaphor. On entry to the system, the student users can choose to go into one of four possible areas; namely, General Office, Study Room, Work Room or Meeting Rooms quickly (see Figure 4). However, if the user is a teacher, the system will channel him/her to the preparation room to produce the course material instead to lead him/her to the study room.

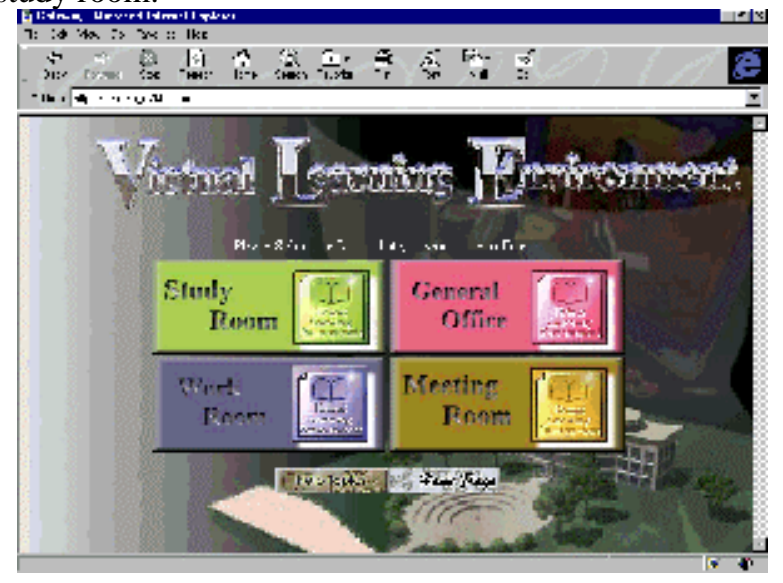

Figure 4. Structure of VLE

Table 3. Different areas of VLE

\begin{tabular}{|c|c|c|c|}
\hline Study Room & Preparation & Student's Wor & Teacher's \\
\hline & Room & Room & Work Room \\
\hline E-book & E-book & Bulletin Board & Bulletin \\
\hline FAQ & Editor & Scrap Book & Board \\
\hline On-line test & Answer FAQ & Group Project & Scrap Book \\
\hline Progress & Test Editor & Reflection & Project \\
\hline Report & Course & Report & Management \\
\hline & Evaluation & Mailing box & Reflection \\
\hline & Report & & Comment \\
\hline & & & Mailing Box \\
\hline Meeting Roc & & $\underline{\text { General Office }}$ & \\
\hline Net-meeting & & Course Inform & ion \\
\hline (Teleconfere & cing) & Personal Inforn & ation \\
\hline & & Changing pas & \\
\hline
\end{tabular}

In the following, we will highlight and illustrate some of the major functions of VLE. 


\section{Multimedia, Interactive Electronic Book (E-book)}

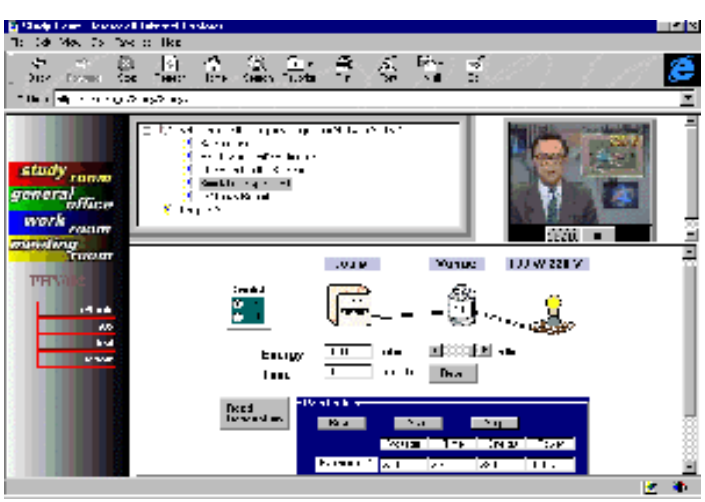

Figure 5 E-book

We are conscious that an organized format like the content outline of a book will be a familiar device to help the readers to easily locate his/her interesting subjects, so our electronic book is designed by using a similar format quickly (see Figure 5). The left-top frame of the presentation panel shows the course outline whereas the bottom frame shows the content of the respective selected reading section, and the right-top frame is a presentation windows that allow the animation or media clips to be shown. Unlike ordinary textbooks, the electronic book we devised can be composed of multimedia and interactive simulation program as well as text. The multimedia components can really stimulate the readers' interest while the simulation program allows the readers to test their understanding by doing experiment virtually.

\section{On-line Authoring (E-book Editor)}

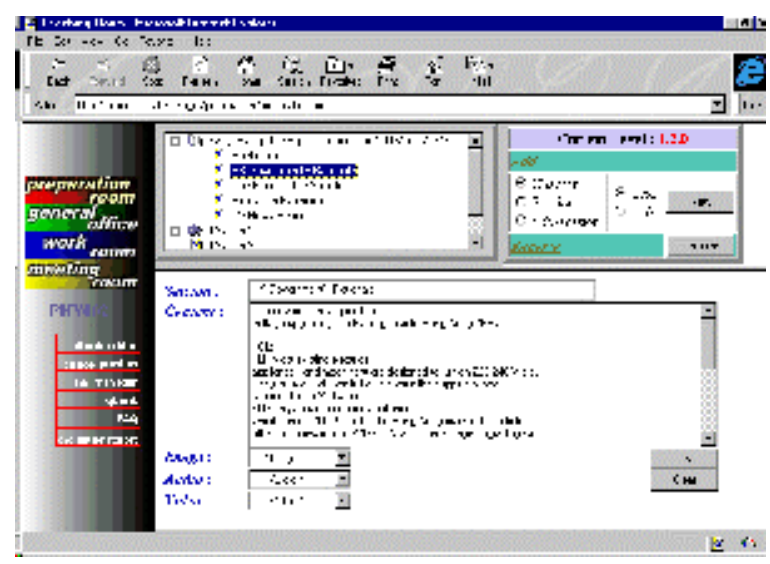

Figure 6 E-book Editor

We understand that most teachers are not technically equipped for developing multimedia courseware or even web page. Therefore, in order to promote the teachers to build their on-line course, our system provides an on-line authoring system, which allows the instructor to construct or modify their materials quickly (see Figure 6). The system takes care of all of the HTMLs so that the teachers can focus his effort on creating good teaching materials. The modification is done on-line and the new course materials can be reflected on the student's terminal as soon as the teaching materials are changed. This authoring system allows the instructors to edit the electronic book as well as the question banks of the specific course.

For the students to test their understanding of the course materials, interactive quizzes are provided to fulfill this purpose. Multiple-choice questions or short questions can be generated based upon the students' preference quickly (see Figure 7). Like other on-line quizzes, these quizzes are automatically graded on the server and the student will get his or her results instantly. The statistics derived from the test results will be shown after the test and references for each answer are given as well.

\section{Interactive Quiz and Self-Assessment}

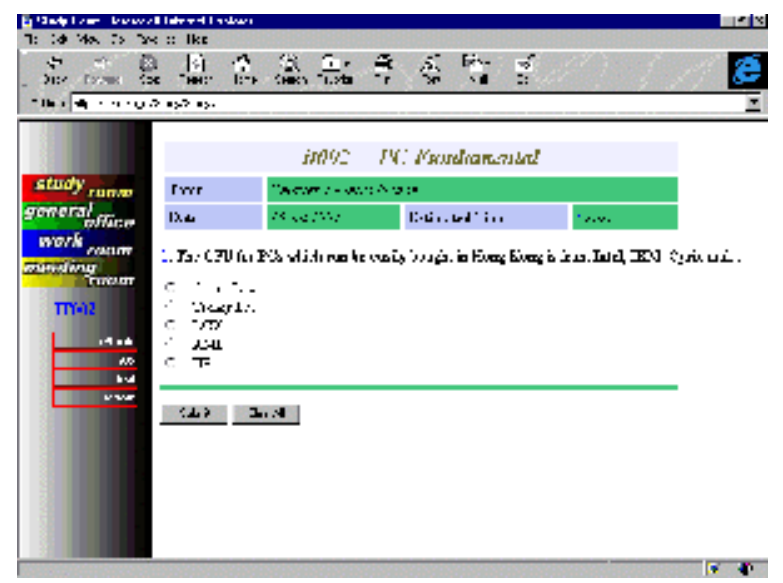

Figure 7 Interactive Quiz

\section{FAQ}

It is always difficult for teachers to handle all the students' questions in the traditional classroom. Either the students are too shy to ask or sometimes the questions being asked are irrelevant. With this FAQ function, students can summit their queries anonymously and the teachers can filter the questions and post their answers for the valid questions quickly. All the posted questions become archives stored in the system. As time goes by, the FAQ will probably become a knowledge base for that specific course which will be more relevant and meaningful to the learning cluster of that specific course. 


\section{Scrapbook}

The remarkable feature of World Wide Web is that it is an evolving knowledge repository. By using some efficient search engines, people can find lots of interesting and useful information for research and various purposes quickly. Seeing this importance, our system facilitates the users with an exploration tool. Apart from providing the users the access to some prominent search engines like Alta Vista or Yahoo, our system provides a bookmark for the users to bookmark the their favorite web sites. The bookmarks are stored in the database in our server instead of being stored on the clients' machines. By doing this, an individual can choose to share his or her collections to the public (all his course fellows) or he or she can choose it for private use. This helps the users to construct a knowledge base for themselves and contribute to that specific course community as well.

\section{Collaborative Teleconferencing}

Teleconferencing was, in the past, considered too expensive technology for a general educational purpose. High bandwidth connection such as the leased line or ISDN and the sophisticated software were needed to set up a teleconference. As the technology moves on, new software technology creates new possibility for using teleconferencing under low bandwidth connection. In our system, we employ the Microsoft NetMeeting as our teleconferencing tool quickly. In our testing, it shows that various teleconferencing functions such as the audiovisual signal transmission, on-line chatting, white board, application collaboration, file transfers can be performed satisfactorily.

\section{System Testing and User Evaluation}

The first phase of the VLE was conducted in Spring 1997. It was a pilot study, which involved 48 first-year HKU students. They were taking the course of the Information Systems in Organizations (ISO) which is equivalent to Introduction to Management Information Systems as offered in most universities. These students used VLE to support their leaning activities and the instructor used it to prepare course materials etc. Details of these activities are as follows:

1. Students, being equally divided into 16 groups, used the E-book function to create electronic lecture notes to share with classmates. Each group was responsible for one chapter out of sixteen. These lecture notes were supposed to cover the important issues and a summary of the chapter. The students were encouraged to search for materials relevant to the subject discussed in local text books. For example, chapter 9 was about telecommunication. The students collected the information about the major information service providers (ISPs), network carriers, and gateways onto the Internet for that chapter, while students of another group prepared a case study about Hong Kong Company for a chapter of Business Process Reengineering.

2. As for interactive quiz and self-assessment tool, students, who were in the same group, were asked to prepare ten questions or problems for their classmates to test themselves and to prepare for the exams.

After the first phase pilot study, we also arranged some interviews to study how they felt about the VLE and how they used VLE to help themselves in their learning and preparation for the exams.

Following are some of the lessons that we have learned:

1. Home page down-loading time is a major concern of the off-campus users who access the system through modem and telephone lines. About one- third (15) did access the VLE via a modem with a dial-in program instead of accessing the VLE using the terminals on campus. We have received a number of e-mail complaining about the limited bandwidth. However, they still appreciated to have an opportunity to use such systems, for example:

"One of the advantages of VLE is that a student can carry out self-study at home. At the present stage, most of us still use 28,800 Kbps connection (I use 14,400 only...) at home. (Traffic jam is one of the great problems on the Internet). A page often needs minutes to load. At this speed, the learning efficiency is very low. I think the page can be redesigned so that the downloading time is short even when browsing at home, and the learning efficiency can be enhanced by this."

In order to solve the problem, we have to redesign most of our home pages so as to minimize the file sizes for the sake of the speed. Although we could use more powerful servers to boost up the performance of server side transaction, some of the problems related to the network bandwidth are tied with the network infrastructure of HKU and they are beyond our control. The computer center of HKU already realized such problem and thus deployment of higher bandwidth network will start next year.

In order to ensure a successful distance learning or web-based learning project, the two most critical factors: the network infrastructure and supports from the university level, should not be overlooked. 
Without such supports, it is difficult to see the impacts of our VLE system.

2. Although the VLE can be used as a complete distance learning system, we have no intention to replace the existing lecturing infrastructure with it in this study. We used it as an auxiliary system to facilitate individual learning. However, it seemed that part of the students have mainly relied on the VLE and textbook to support their learning. Based on the results of their final examination, we did not see any significant difference among those students who constantly attended lectures and those who were virtual students (at least ten of them, having attending less than thirty percent of the lectures). The outcome show that the Internet can be an alternative way for learning but the data, seemingly, is not sufficient to give any further inference. Besides, the traditional examination might not be the best testing instrument for investigating learning effectiveness. In the next phase of our research, we will adopt some of the educational research designs and instruments which shall be more appropriate presumably.

3. Interaction and prompt reaction from the instructors are important. Students always tried to see how dynamic or responsive the VLE was. Whenever students had problems, they sent them immediately through the VLE to the instructors. Then they started to count how long that would take for the instructor to send their responses. For students, such response time is an important measure of system's performance. However, this would tie the instructor, in most cases the teaching assistants, to the terminal.

\section{Conclusion}

The pilot study is essential as it shows the capacity of our existing system. It was able to support one class of 48 students. In the fall semester of 1997, a formal experiment will be conducted in three different departments in HKU to see whether or not VLE is able to support teaching and learning. In order to collect different sorts of data, we will use a system logging program to study the patterns of usage of the VLE. For example, we will study what the busy periods are, the peak loading on both the system and the network as well as what percentages of users are on the same network (through FDDI and high-bandwidth Ethernet).

In the future, we expect the VLE will be used not only to support the teaching and learning at HKU, but also inter-university learning. Many universities offer similar curricula and therefore may use the same teaching materials. For example, ISMT 101
(Introduction to Information Systems) of HKUST, 23127 (Information Systems in Organization) at HKU, and MIS 111 (Introduction of Management Information Systems) at the University of Arizona used the same textbook in the past. Without paying too much coordination efforts, VLE will enable the students from these institutes to learn and explore together. Lecturers can also design and create teaching materials together. To support international collaboration is another goal of VLE.

Furthermore, with its accessibility to remote resources, its possibility to make virtual collaboration with researchers at other institutions and its efficiency of dissemination of research findings over the Internet, VLE undoubtedly can enhance academic staff's research and scholarly productivity in the new era.

\section{References}

[1] Alavi, M., Wheeler, B.C., and Valacich, J.S. (1995), Using IT to Reengineer Business Education: An Exploratory Investigation of Collaborative Telelearning," MIS Quarterly (19:3), September 1995, pp. 293-312

[2] Alexander, S., (1995), "Teaching and Learning on the World Wide Web", Proceedings of the First Australian World Wide Web (AusWeb95). Accessible at "http://www. scu.edu.au/ausweb95/ papers/ education2/alexander/"

[3] Berge, Z. (1995). Computer-Mediated Communication and the On-line Classroom in Distance Learning", Computer-Mediated Communication Magazine, Vol. 2:4, pp. 6-13.

[4] Farquhar, J., (1995), "The Internet as a Tool for the Social Construction of Knowledge". Assessable at "http://www.hbg.psu.edu:80/ jxf18/research/sc\&i.html

[5] Frick, T. W. (1991). restructuring Education through Technology", Fastback Series No. 326, Bloomington, IN: Phi Delta Kappa Educational Foundation.

[6] Gagne' R. M., Birggs, L. J. and Wager, W. W., (1992), " Principles of Instructional Design" , Fort Worth, Harcourt Brace Jovanovich College Publishers

[7] Gagne' R. M., Driscoll, M. P., (1988), " Essentials of Learning for Instruction" , New Jersey, Prentice Hall

[8] Hiltz, S.R., (1994), The virtual classroom : learning without limits", Norwood, N.J., Ablex Pub. Corp.

[9] Hiltz, S.R., (1995), "Teaching in a Virtual Classroom", Reprints of Invited papers for: 1995 International Conference on Computer Assisted Instruction ICCAI'95, March 7-10, 1995, National Chiao Tung University, Hsinchu, Taiwan.

[10] Honebein, P. C., Duffy, T. M. and Fishman B. J., (1993), "Constructivism and the Design f Learning Environments: Context and Authentic Activities for Learning", in Duffy, T. M., Lowyck, J. and Jonassen, 
D. H. (1992) (ed.), Designing Environments for Constructive Learning. New York, Springer-Verlag

[11] Hutchison, C., (1996), "The 'ICP on-line': Jeux sans fronties on the CyberCampus", Journal of ComputerMediated Communication, Vol. 1, No. 1. Accessible at "http://cwis.usc.edu/dept/annenberg/ vol1/issue1/hutchison/CHRISR.html"

[12] Johnson, D. W. and Johnson, R. T., "Learning Together and Alone", Boston, Allyn and Bacon.

[13] Jonassen, D., Mayes, T. and McAleese R., (1993), "A Minifest for a Constructivist Approach to Uses of Technology in Higher Education", in Duffy, T. M.,

[14] Lowyck, J. and Jonassen, D. H. (1992) (ed.), Designing Environments for Constructive Learning. New York, Springer-Verlag

[15] Kearsley, G., Seidel, R. \& Park, D.K. (1993). Theory Into Practice. A hypertext Database for Learning and Instruction, US Army Research Institute.

[16] Kerr, N. \& Brunn, S. (1983), he dispensability of member effort and group motivation losses: Free-rider effects" Journal of Personality and Social Psychology, 44, 78-94.

[17] Knuth, R. A. and Cunningham, D. J., (1993), "Tools for Constructivism", in Duffy, T. M., Lowyck, J. and Jonassen, D. H. (1992) (ed.), Designing Environments for Constructive Learning. New York, Springer-Verlag

[18] Kozma, R. B.(1991), "Construction Knowledge with Learning Tool", in Kommers, P.A.M., Jonassen, D. H. and Mayes, J. T. (1991) (ed.), Cognitive Tools for Learning. New York, Springer-Verlag

[19] Leidner, D. E., Jarvenpaa, S. L., (1995), "The Use of Information Technology to Enhance Management School Education: A Theoretical View", MIS Quarterly, September, 1995, pp. 265-291.

[20] Oonnell, J. J. (1995). Teaching with Technology", PENNPRINTOUT, Vol. 11:5, March 1995

[21] Ryder, M. and Wilson B., (1995), "From Local to Virtual Learning Environments: Making the Connection", accessible at "gopher://OASIS.Denver. Colorado.EDU/h0/UCD/dept/edu/IT/ryder/aera95"

[22] Ryder, M., (1994), "Augmentation of the Intellect: Network Instruments, Environments and Strategies for Learning", accessible at "gopher://OASIS.Denver. Colorado.EDU/h0/UCD/dept/edu/IT/ryder/augment"

[23] Schneider, D., 1994, "Teaching \& Learning with Internet Tools"; A Position Paper presented at the Workshop on "Teaching \& Learning with the Web" at the First International Conference on the World-Wide Web, 1994 at CERN, Geneva. Accessible at http://tecfa.unige.ch/eduws94/contrib/schneider/schneide.fm.html\#HDT0

[24] Spath, P., 1992, Design Considerations in Hypermedia Tutorials", in Oliver, A. (1992) (ed.), Hypermedia Courseware: Structures of Communication and Intelligent Help. New York, Springer-Verlag

[25] Turoff, M., (1995), "Designing a Virtual Classroom", Reprints of Invited papers for: 1995 International Conference on Computer Assisted Instruction ICCAI'95, March 7-10, 1995, National Chiao Tung University, Hsinchu, Taiwan.
[26] Winn, W., (1993), "A Constructivist Critique of the Assumptions of Instructional Design", in Duffy, T. M., Lowyck, J. and Jonassen, D. H. (1992) (ed.), Designing Environments for Constructive Learning. New York, Springer-Verlag

[27] Wittrock, M. C., (1991), "Model of Heuristic Teaching", in Marjoribanks, K. (1991) (ed.), The Foundations of Students' Learning, Sydney, Pergamon Press

Hypertext reference

[Href1] Vision, Progress Report of HKU vice-chancellor's Ad Hoc Group for Learning Technologies.

[Href2] The Virtual Classroom The University of West Florida. http://www.vclass.uwf.edu/

[Href3] The World Lecture Hall University of Texas. http://www.utexas.edu/world/lecture/index.html

[Href4] ElectronicCourse Reserves - The University of Connecticut

[Href5] A Report by the University Grants Committee, Chapter 26: Present and Future Teaching Methodologies. http://www.ssrc.hku.hk/ugcweb/hervw/CHAPTE26.htm 1

[Href6] The Net - Technical difficulties. http://www. news.com/SpecialFeatures/0,5,8360,00.html

[Href7] Blue Web'n Library. http://www.kn.pacbell. com/wired/bluewebn/

[Href8] Netday. http://www.netday96.com/

[Href9] SUNNY Virtual Classroom. http://137.142. 42.95/west/SVC.html

[Href10] CORAL system. http://coral.cis.nctu.edu.tw

[Href11] Spectrum University. http://www.vu.org/ campus.html

[Href12] ZDU Net University. http://www.zdu.com http://mmedia.ucc.uconn.edu/VirtualReserve

[Href13] FirstClass Systems Corporation http://www.firstclass.ca/

[Href14] Quick Overview of Topclass

http://www. wbtsystems.com/

[Href15] WebCT http://homebrew.cs.ubc.ca/webct/ webct.html 